\title{
The Rice Value Chain: a Case Study of Thai Rice
}

\author{
Benjavan Rerkasem
}

\begin{abstract}
Plant Genetic Resource and Nutrition Laboratory, Chiang Mai University, Chiang Mai 50200, Thailand

Corresponding author.E-mail: benjavan.r@cmu.ac.th

https://doi.org/10.12982/CMUJASR.2017.0001
\end{abstract}

$\mathrm{T}$

he rice value chain has been transforming throughout Asia since the 1990s, although with some unique differences in Thailand. Starting from the farm, the Thai rice value chain behaves more like a collection of streams than a monolithic chain, as in other countries. In Thailand, different types and grades of rice are kept separate throughout the value chain, starting from the point of production ('upstream'), continuing through its processing, storage, and marketing ('midstream'), and ending with different consumer groups ('downstream'). This paper describes the ecological, socio-economic, technical, and management conditions that underlie the rice value chain in Thailand. Upstream, a wealth of local varieties, strengthened by support from a publicly-funded, national, rice breeding program and seed system, allows rice farmers in Thailand the choice of growing either traditional varieties with premium quality and price or modern high-yielding varieties, as dictated by their own ecological and economic circumstances and preferences. Midstream, the paddy harvest from a multitude of farms is sorted into different branches of the value chain as rice of different types and grades are separately processed, stored and marketed. Paddy price differentials are signaled back upstream to influence farmers' decision in the next season. Innovations of mechanical drying and parboiling facilitate fragmenting the paddy market into 'dry' and 'green' rice, each with different price setting criteria. Increased production of modern high-yielding varieties, which is milled into ordinary white rice, has not led to a glut in the market, because of demand from the parboiling industry. The Thai government has played an important role in securing property rights to Thai Hom Mali, the brand name for Thai jasmine rice, in important export markets, as well as enacting laws that explicitly define the grades for differently priced types of milled rice. Technological innovations, including combine harvesting that has reduced labor costs as well as grain breakage during milling due to timely harvesting, mechanical drying and parboiling, novel utilization of the rice husk as fuel, and extraction of high quality oil from the rice bran, have all added 
substantial value to each ton of rice. Downstream, pre-packaged, branded rice has become the norm in small provincial and district markets, as well as supermarkets in urban centers. Development of local, small-and medium-sized, modern mills has allowed farmers to enter the retail milled-rice market and facilitated development of new branches of the value chain with the emergence of local specialty rice.

Keywords: Grain quality, Value chain, Rice

\section{INTRODUCTION}

Since the 1990s, the rice value chain in Asia has been transforming (Reardon et al., 2012; Reardon et al., 2014). While Thailand was not covered in this survey of Asia's rice producing countries, many of the same changes have taken place with Thai rice (Rerkasem, 2015). Upstream, on-farm rice production has become mechanized, often by employing service providers to prepare the land and to plant and harvest the rice; this has been accompanied by increased use of fertilizer and other chemical inputs, along with improved seed. Midstream, paddy processing has been transformed with improved milling facilities, packaging, and branding. Downstream, in the retail milled-rice market, consumers no longer buy loose rice by the litre or kilogram out of hemp sacks, but choose from branded, pre-packaged rice in the so-called 'supermarket revolution'.

The many types and grades of Thai rice are the product of the entire value stream, from the upstream agro- diversity described by "the many and changing ways in which farmers manage diverse genetic resources and natural variability, and organize their management in dynamic social and economic contexts" (Brookfield, 2001); to the midstream technological and socioeconomic forces driving management and quality control by paddy buyers, mills, and processors; and ending with the retailers, exporters, and varying preferences of different consumer groups. Performance of the value chain is adjusted and improved as retail price information is fed back upstream to influence the mills and ultimately farmers' varietal and management choices.

\section{DIFFERENT RICE FOR DIFFERENT PEOPLE}

Thai rice includes four major price- and market-differentiated types of milled rice, namely White rice, Thai Hom Mali rice, parboiled rice, and glutinous rice (Figure 1). 


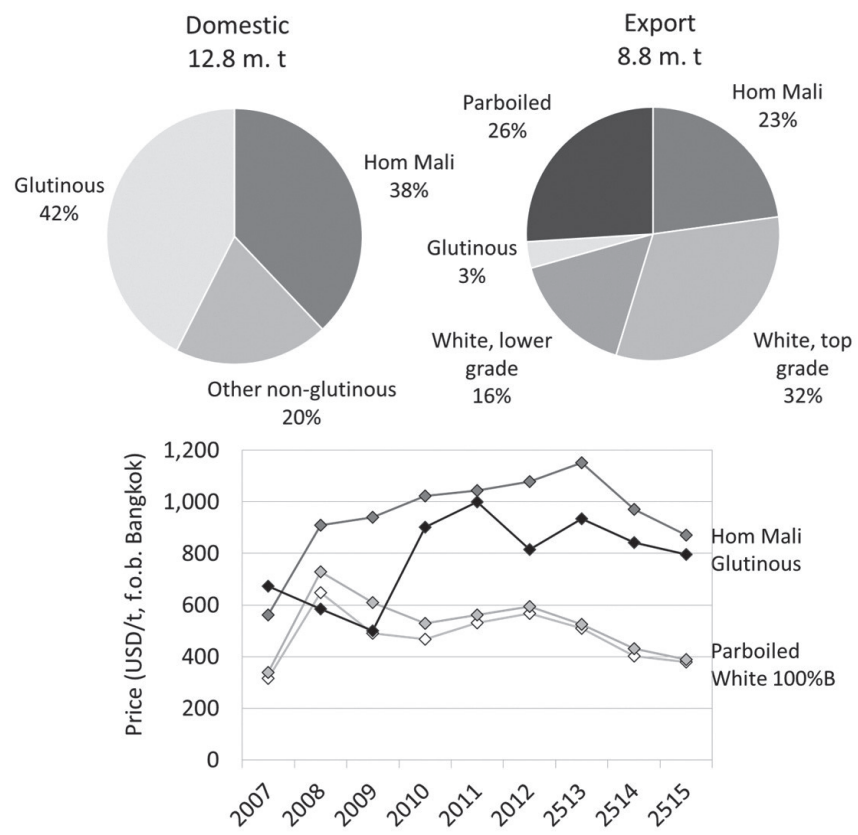

Figure 1. Main types of Thai rice (averages for 2014-16 in milled rice) consumed domestically (upper left) and exported (upper right), and their long term prices.

Source: Calculated and drawn with data from $\operatorname{OAE}(2014,2016 a, 2017)$.

In the milled-rice market, the term White rice, produced largely from modern high-yielding varieties, refers specifically to ordinary, non-aromatic, non-glutinous rice, although raw milled rice is essentially all white in color. Parboiled rice, also processed largely from modern high-yielding varieties with non-glutinous grain, is cooked by steaming in the husk before milling. Thai Hom Mali is an aromatic Thai jasmine rice with premium quality and price; as of 2002, the brand is a registered trademark in 55 countries (DFT, 2011). Only limited statistics are kept for the relatively minor production and lower-priced aromatic rice, called Hom or Hom Pathum (8\% of the volume and $5 \%$ of the value of aromatic rice exports in 2015-16, data in OAE, 2017). Based on longterm averages, White rice is generally the cheapest type of rice. Compared to White rice, parboiled rice is only slightly (3-5\%) more expensive, glutinous rice is considerably (about twothirds) more expensive, and Hom Mali is the most (nearly double) expensive. But these average differences hide a much wider range of choices in grades and prices for those buying and selling rice. Experimental auctions in Africa have demonstrated the willingness of consumers to buy more expensive grades of milled rice, depending on both extrinsic attributes (such as appearance, freedom from foreign matter and contaminants, and 
packaging) and intrinsic characteristics that affect its cooking and eating quality (Demont \& Ndour, 2015). Similarly, in Thailand, the quality of milled rice is judged by its physical appearance, including whiteness, grain glossiness, translucency, freedom from chalkiness (opaque area in the otherwise translucent grain of non-glutinous rice), and yellow and red rice; as well as its internal characteristics that determine the taste and feel of the resultant cooked rice. For top-grade rice, after de-husking, the rice is polished to remove the bran in such a way as to produce a milled grain that is pure white with a glossy shine; this may require special modifications during milling, including spraying water. The term Suay Ngarm (beautiful) is commonly used to describe the appearance of different types of milled rice; it is also a legal term to describe rice (e.g., see MoC, 2016a; 2016b; 2016c).

Most of Thailand's annual production of 5-7 million tons of glutinous rice is consumed domestically, mostly in the upper North and much of the Northeast, where it is the everyday staple, and in the rest of the country as part of the popular Isan cuisine; only $2-5 \%$ is exported. Parboiled rice, on the other hand, is destined entirely for export; it is little known in Thailand, except among those involved in the industry and trading. Non-glutinous rice in the domestic market is differentiated into a high-amylose ( $>24 \%)$ type, with a dry and firm texture when cooked, and a low-amylose (10-20\%) type, with a moist and soft texture when cooked, which is often also aromatic. The domestic market for aromatic rice is primarily high-income consumers in urban centres. The high-amylose, or dry and firm-textured rice is traditionally preferred by people of the Central Plain, in the provinces surrounding the old capital of Ayutthaya, and among the urban poor, who judge rice quality primarily by its ability to expand in volume after cooking, colloquially termed Hoong Kuen Mor (rising in the pot). The firm-textured rice is considered more economical, as the rice with higher amylose content has a greater volume expansion ratio (cooked rice volume relative to its precooked volume) (Hussain et al., 1987; Mohapatra \& Bal, 2005). Street food venders prefer the dry and firm rice to the soft and moist aromatic rice, not only for its economics, but also because it does not spoil as fast in the tropical heat. A famous source of the best dry and firm-textured, non-glutinous rice is Sao Hai, a district in Saraburi province in the Central Plain. The name Sao Hai has become a generic brand name for this entire category of lowerpriced, dry and firm-textured rice found in retail markets throughout Thailand. The name is rarely specific to a variety, and often applies to any high-amylose, modern, mega-variety. It usually sells for half or less the price of Hom Mali. However, some Sao Hai-type rice tends to harden when cold; those who consume their rice hours after cooking, still a common practice for many Thais in spite of the electric rice cooker, find this objectionable. 
Stability in the lower range of gelatinization temperature, at which the crystalline structure of starch dissolves and becomes gel-like in consistency (Fitzgerald et al., 2009), i.e. for the cold cooked rice to 'stay soft', is desirable for cold rice preparations, including Khanom Chin (Thai rice noodle) and Japanese sushi. The genotype and environmental interactions can influence the gelatinization temperature. Cold cooked rice derived from crop grown in the hot season hardens much more than that grown in the wet season; this seasonal effect is much stronger in softer varieties PTT1 and RD21 (15-20\% amylose) than in the firm-textured CNT1 and SPR1 (26$29 \%$ amylose) (Laenoi et al., 2017). The alkali spreading assay ranks the degree of disintegration of raw milled rice grain in alkali solution on a 1-7 scale that correlates inversely with the gelatinization temperature (Little et al., 1958; Juliano \& Villareal, 1993). It is a simple test of milled rice for predicting the eating quality of its cooked rice, including rice products that are eaten cold, relative to the standard alkali spreading (AS) values for RD4 (2) and KDML105 (7). The gelatinization temperatures of non-glutinous rice with low amylose, including the Hom Mali variety KDML105 (12$17 \%$ amylose), are typically low, while those with higher amylose are higher, such as CNT1 and SPR1 with AS values of 3 . However, the relationship between amylose content and gelatinization temperature does not appear to be straightforward, as the glutinous variety RD4, a standard for high gelatinization temperature, has almost no amylose (Laenoi et al., 2017). Although RD4, along with RD2, were Thailand's first modern glutinous rice varieties (released in 1973 and 1969, respectively), farmers did not adopt the varieties, as they were considered barely edible because the resultant cooked rice was extremely hard when cold.

Different types of rice are exported to different countries (Figure 2), with some year to year variations in some countries and steady growth trends in others (Figure 3)

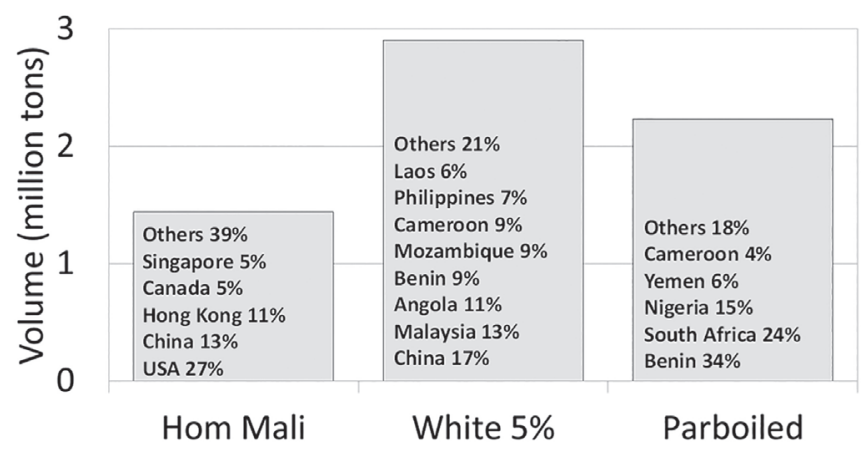

Figure 2. Main importing countries of Thai rice by type in 2015-16.

Source: Drawn with data from OAE (2017). 


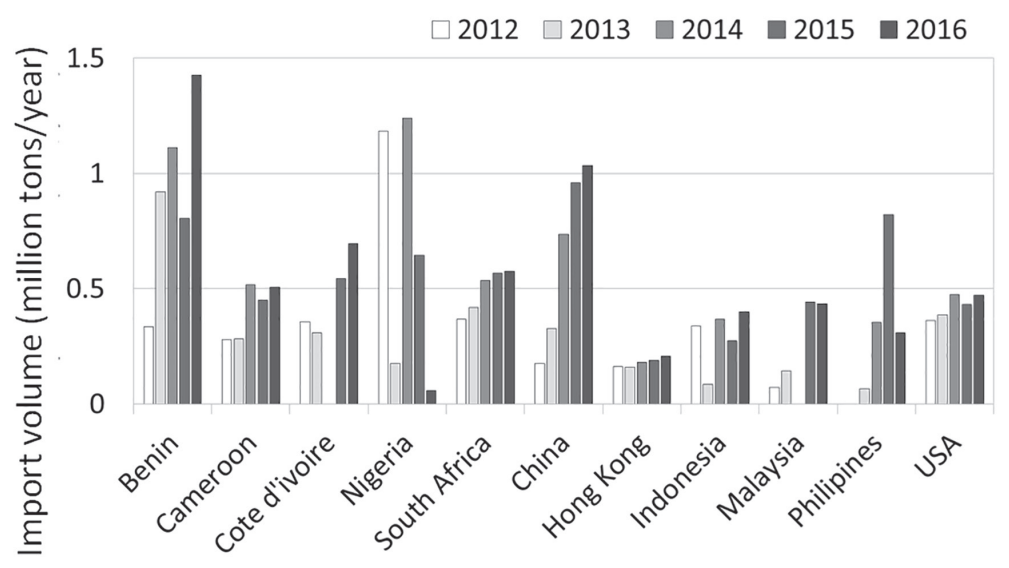

Figure 3. Year-to-year variation in the import volume of Thai rice in selected countries.

Source: Drawn with data from TREA (2017).

From 2012 to 2016, Thai rice exports to Nigeria, Cote d'Ivoire, Indonesia, Malaysia, and the Philippines fluctuated widely, while steadily increasing trends were seen in others, notably China with 0.24 million tons year-on-year growth. The high-end markets for the top-priced Hom Mali was consistently dominated by the United States, followed by China and Hong Kong. The lower-priced white rice was exported more widely to countries in Asia and Africa. Eightyfour percent of the parboiled rice export in 2015/16 went to just five countries: Benin, South Africa, Nigeria, Yemen, and Cameroon. Despite being a significant importer of parboiled rice, the bulk of Cameroon's imports was White rice $(74 \%)$. China, in contrast, imported no parboiled rice, with its imports split between White rice (72\%) and Hom Mali (28\%).

\section{THAI RICE CROPPING SYSTEM}

Within ecological limits, farmers choose the variety of rice to plant, often based on last year's prices. For example, the glutinous rice glut and corresponding price drop in 2017 was generally believed to have resulted from farmers switching from non-glutinous to glutinous rice in response to the exceptionally high glutinous rice prices in 2016 (Prachachat Business-news, 2017). Modern high-yielding rice varieties have been widely adopted in most rice-growing countries in Asia, including Bangladesh, China, India, Indonesia, Malaysia, Philippines, and Vietnam (Lipton \& Longhurst, 1989; Kaosa-ard \& Rerkasem, 2000). In Thailand, while the contribution of modern rice varieties has increased since the first varieties were released in 1969, traditional, photoperiod-sensitive, tall- 
plant varieties still accounted for more than one-half of the wet season rice area in the early 2010s (Figure 4). Due to their much higher yields, modern varieties accounted for $55 \%$ of Thailand's 2013/14 paddy production, i.e. wet season 2013 plus dry season 2014, from only $44 \%$ of the crop area. Three traditional, photoperiod-sensitive, tallplant type with superior grain quality and genetically closely related KDML105, RD15, and RD6 made up 53\% of the wet season production, and three other mega-varieties contributing an additional 15\% (Table 1). KDML105 (Khao Dawk Mali 105) was developed in 1950 by pure line selection from a farmer's local variety in Bang Khla, Chachoeng Sao (now almost a suburb of Bangkok); RD15 and RD6 were developed from KDML105 by mutation breeding (Rice Department, 2016).

The geographical distribution of the different types of rice is influenced by the strong location effect on the grain quality of aromatic rice, as well as local preferences and availability of dry-season irrigation (Figure 5). The best Hom Mali is produced in the Northeast and in some of the Northern provinces, including Chiang Rai, Phayao, and Chiang Mai. Glutinous rice is grown almost entirely in the Northeast (70\%) and upper North (30\%). The dry-season rice crop is concentrated in the Plain of the Chao Phraya River, in the lower North and Central region.
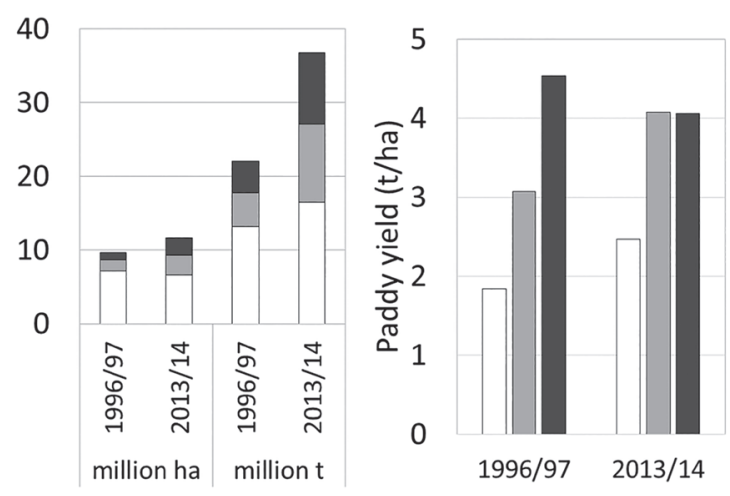

Figure 4. Contributions to Thai rice production from traditional ( $\square$ wet season) and modern ( $\square$ wet season, $\square$ dry season) varieties in 1996 and 2013 (left) and their yield (right).

Source: Drawn with data from OAE $(1998,2014)$. 
Table 1. Distribution of different types and varieties of rice produced in the wet and dry season in different regions of Thailand in the 2013/14 growing season $^{1}$

\begin{tabular}{|c|c|c|c|c|c|}
\hline \multirow{2}{*}{$\begin{array}{l}\text { Season } \\
\text { Plant type/variety }\end{array}$} & North & Northeast & Central & South & Country \\
\hline & \multicolumn{5}{|c|}{ Paddy production (m. t at $15 \%$ moisture) } \\
\hline \multicolumn{6}{|l|}{ Wet season } \\
\hline \multicolumn{6}{|c|}{ Traditional, photoperiod-sensitive, tall-plant type } \\
\hline \multicolumn{6}{|l|}{ Non-glutinous } \\
\hline KDML105² & 1.090 & 6.465 & 0.402 & 0.002 & 7.958 \\
\hline $\mathrm{RD}^{1} 5^{2}$ & 0.149 & 0.496 & 0.002 & 0.000 & 0.648 \\
\hline \multicolumn{6}{|l|}{ Glutinous } \\
\hline RD6 & 1.367 & 4.395 & 0.008 & 0.000 & 5.770 \\
\hline Unspecified $^{3}$ & 0.740 & 0.682 & 0.422 & 0.194 & 2.038 \\
\hline \multicolumn{6}{|c|}{ Modern, photoperiod-insensitive, semi-dwarf, high-yielding type } \\
\hline CNT1 & 0.895 & 0.043 & 0.223 & 0.052 & 1.213 \\
\hline SPR1 & 0.889 & 0.007 & 0.952 & 0.007 & 1.854 \\
\hline $\mathrm{PTT} 1^{4}$ & 0.289 & 0.008 & 0.597 & 0.012 & 0.905 \\
\hline Others ${ }^{5}$ & 3.219 & 0.196 & 3.133 & 0.150 & 6.698 \\
\hline Total wet season & 7.972 & 11.675 & 5.341 & 0.248 & 25.234 \\
\hline \multicolumn{6}{|l|}{ Dry season } \\
\hline \multicolumn{6}{|c|}{ Modern, photoperiod-insensitive, semi-dwarf, high-yielding type } \\
\hline Unspecified $^{4}$ & 3.979 & 1.215 & 4.348 & 0.13 & 9.672 \\
\hline Total crop year $2013 / 14$ & 12.617 & 13.506 & 10.086 & 0.547 & 36.756 \\
\hline
\end{tabular}

Source: Data from OAE $(2014,2016 a)$.

Note: ${ }^{1}$ The rice year in Thailand begins with the wet season crop in May and ends with the harvest of the dry season crop in April of the following year; ${ }^{2}$ Producing aromatic Hom Mali; ${ }^{3}$ Non-glutinous and glutinous local varieties; ${ }^{4}$ Producing aromatic Hom or Hom Pathum; 5Includes non-glutinous PSL2, glutinous SPT1 plus other modern varieties from Thailand's national breeding program and modern glutinous varieties from Lao PDR, as well as 'escaped' breeding lines from yield trials. 

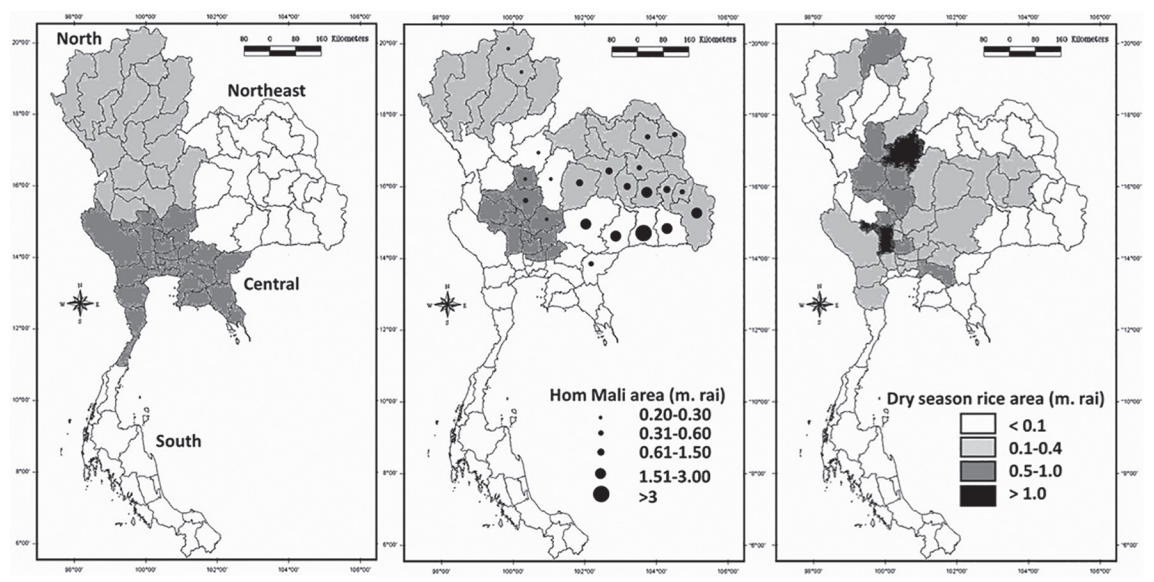

Figure 5. Thailand's agricultural regions (left); main glutinous rice producing provinces, $\mathbf{\square}$ area with traditional preference for rice with a dry, firm texture when cooked, and Hom Mali area by province (center); and dry-season rice area by province (right).

Source: Drawn with data from OAE (2014, 2016b).

Note: 1 rai $=1,600 \mathrm{~m}^{2}$.

For the cultivation of a single crop species, the Thai rice cropping system is diverse, with different cropping patterns that combine rice varieties with different plant and grain types (Figure 6). Thai rice varieties are classified by their adaptation to the growing seasons, based on their sensitivity to photoperiod or day length. Photoperiod-sensitive varieties can be grown only in the wet season; the short-day trigger in August or September is essential for them to flower and produce yield normally. Photoperiod-insensitive varieties can be grown in either the dry or wet season, as their flowering is insensitive to changes in the length of day in Thailand (11-13 hours). 
$\begin{array}{llllllllllllllllll}\mathbf{J} & \mathbf{A} & \mathbf{S} & \mathbf{O} & \mathbf{N} & \mathbf{D} & \mathbf{J} & \mathbf{F} & \mathbf{M} & \mathbf{A} & \mathbf{M} & \mathbf{J} & \mathbf{J} & \mathbf{A} & \mathbf{S} & \mathbf{O} & \text { Water supply }\end{array}$

1. Traditional

2.

Flood

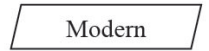

3. Traditional

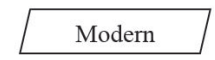

4.

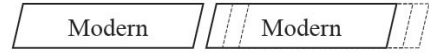

Rainfed Photoperiod-sensitive, traditional varieties with tall-plant type and non-glutinous or glutinous grain, depending on locality and price

Irrigated Flood-prone area, wet-season crop postponed to avoid flooding, dry-season crop with modern, photoperiod-insensitive, high-yielding varieties.

Irrigated Upper North and Northeast; traditional, photoperiod-sensitive glutinous or high-quality aromatic variety in wet season and modern, high-yielding glutinous or non-glutinous variety in dry season.

Irrigated Lower North and Central region; modern photoperiod-insensitive, high-yielding varieties grown on same land twice a year.

5. \begin{tabular}{|l|l|l|l|l}
\hline Modern & Modern $/ /$ Modern & Irrigated Lower North and Central region; modern,
\end{tabular} photoperiod-insensitive, high-yielding varieties grown continuously without consideration for the season, with 5 crops in two years to 3 crops per year.

Figure 6. Main rice cropping patterns in Thailand.

In rainfed areas, a single wet-season rice crop is usually planted with photoperiod-sensitive, traditional varieties of the tall-plant type and either non-glutinous or glutinous grain. Where irrigation is available, the wet-season rice is followed by another crop in the dry season. Since the sharp decline in the production of soybeans and mung beans in the 1980 s, once the main dry-season crops following wet-season rice, rice has become the sole crop in Thailand's paddy fields. While the wet-season varieties vary by region, the dry-season rice that follows is photoperiod-insensitive modern varieties. In the lower North and Central region, modern varieties are planted in the double wet-dry crop, or in complete disregard of the season with up to three crops on the same land in one year. Modern varieties also enable farmers in flood prone areas with access to dry-season irrigation to avoid the annual floods by postponing planting until the dry season, when the flood has receded (Sommut, 2003). In the upper North and Northeast, higherpriced, photoperiod-sensitive, traditional varieties of the tall-plant type and either non-glutinous or glutinous grain are planted in the wet season, followed in the dry season by modern varieties with either grain type, depending on their relative prices and the locality. The glutinous variety RD6 tends to dominate in the wet season in Northern and Northeastern provinces, where glutinous rice is the locally preferred staple. The essentially identical seasonal adaptations of RD6 and the nonglutinous KDML105 make the varieties completely interchangeable, allowing farmers to respond to their relative prices. Some RD6 has been replaced by photoperiod-insensitive, high-yielding, modern, glutinous varieties with acceptable 
grain quality, including SPT1 (San-pahtawng 1), which was developed at the Chiang Mai Rice Research Center and released in 2000 (Rice Department, 2016), and modern glutinous TDK (Tadokham) varieties from Lao PDR, as well as 'escaped' genotypes from yield trials coordinated by the Ubon Ratchathani Rice Research Center in the 1990s. Unlike the non-glutinous Hom Mali rice, for which high quality and high yield have been shown to be mutually exclusive (Suwanarit et al., 1996), and concentration of the aromatic compound 2-acetyl-1- pyrroline (2AP) to be negatively associated with grain yield and grain nitrogen concentration (Poomipan et al., 2017), the high-yielding advantage of modern glutinous rice varieties has not been shown to have any negative association with grain quality. With paddy of varying types and grades coming out of the farms, where more than one type of rice may be grown side-by-side in the same year or in the same field in alternating years, the high-quality standards demanded by consumers is maintained by stringent control in the midstream section of the value chain.

\section{QUALITY AND PRICE DIFFERENTIATION IN THE PADDY MARKET}

Although the term 'rice quality' means different things to different people, the view that grain quality to farmers means the quality of the seed as planting material and dryness of the grain for consumption, while millers and traders focus on low moisture, varietal integrity, and milling yield (Juliano, 1993) is somewhat static, and fails to capture important quality controlling feedbacks in the Thai rice value chain. Interviews with paddy buyers, mill operators, and farmers revealed how the paddy market operates as a place for sorting rice from the multitude of farms (Rerkasem, 2007; Prom-u-thai, 2010). The price-differentiated paddy bought from farmers enters into branches of the rice value chain in which the rice of different types and grades are separately processed, stored, and marketed, while signalling back upstream to influence the choice of variety, type of rice, and other farming management decisions in the next season. At the high end of the market, the cost of managing the separate streams appears to have been more than compensated for by the premium prices. Quality improvement at the low end of the market for humanitarian purpose, e.g., biofortification with iron, zinc, and other micronutrients for better nutrition of low-income consumers, while achievable without additional on-farm production costs (e.g., Ram et al., 2016), must also negotiate this quality-sorting step, but without the incentive of higher prices. Determinants of the price that farmers are paid for their paddy include type of rice, moisture content (expressed as weight of water as percentage of the paddy weight), potential milling quality, and freedom from contaminations. 


\section{Types of Thai rice}

Quality control is imposed on farmers' varietal and management choices by the price paid for their paddy harvest, which correlates well with the price for the main types of milled rice in the domestic and export markets, but with further differentiation within each type (Figure 7). The megavarieties are generally well recognized by name, but the varietal name is not always indicative of quality and price, because of the strong interaction effects between genotype and environment. By law, Hom Mali rice can only be produced in the wet season from either KDML105 or RD15 (MoC, 2016a), but the rice grown from these varieties does not always fetch the premium price of Hom Mali due to variations in the intensity of the aroma and/or physical attributes of the milled grain (Leesawatwong et al., 2003). Hom Mali of the same grade is further differentiated by price into 'new rice' from the recent harvest, and higher-priced 'old rice' from the preceding season. On the other hand, glutinous rice produced from the variety RD6 (the traditional, photoperiodsensitive variety with tall-plant type) from the Northeast is priced some $15-20 \%$ lower than the same variety grown in the North. Paddy buyers are highly skilled in distinguishing varieties from appearance of the paddy, e.g., a half-mm difference in grain length, while many have the nose for intensity of the aroma in the case of aromatic varieties. The lower-priced aromatic variety PTT1 is distinguishable from KDML105 by its slightly darker husk color and the presence of a short awn in some unhusked grains. However, external appearance of the paddy alone has become less reliable as an indicator of quality since the spread of weedy rice in the 2000s (Maneechote et al., 2004); this rice may have 'mimicked' the cultivated varieties on the outside (Wongtamee et al., 2017), but not necessarily in the quality of the grain inside the husk.

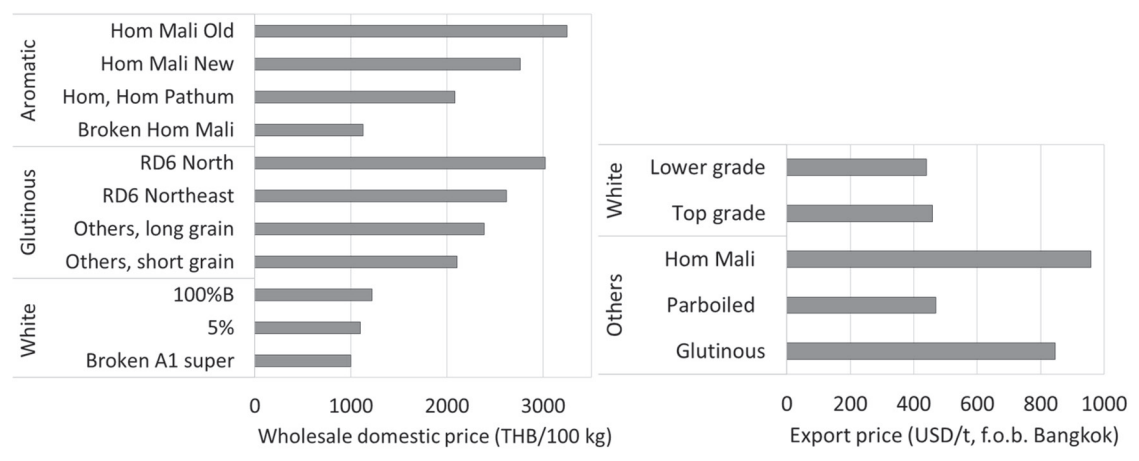

Figure 7. Prices of different types and grades of milled Thai rice in the domestic (left) and export (right) markets.

Source: Drawn with data from TMA (2017); OAE (2017).

Note: 1 USD = 35 THB in 2017. 
Moisture content and milling quality

The rice plant is considered to have reached maturity when $80 \%$ of the grain on the main stem has turned golden yellow. However, the moisture content of paddy harvested at this stage is still $20 \%$ or more; this will result in a lot of broken grain if immediately milled and spoilage if stored, as the optimum moisture content for paddy milling and storage is $14 \%$ (IRRI, 2015). The advent of mechanical drying and parboiling has allowed farmers to sell their paddy with 20-30\% moisture content or higher without a corresponding price reduction for expected milling breakage. The paddy trade has split into separate markets for dry and green or fresh paddy, with different price-setting criteria. In the dry-rice (14-15\% moisture) market, which generally deals with the main, wet-season harvest of superior quality rice, price is based on the potential milling quality estimated by paddy crushing (Figure 8) or sample milling (using machines for de-husking and bran removal of 100-200 g paddy samples), to reveal physical attributes of the grain under the husk as well as its resistance to milling breakage.
Prices of green paddy, which take into account the water weight, converge when adjusted to the same moisture content. The milling yield of head rice and full grain, which is an important price determinant of dry paddy, is of minor consequence for green paddy destined for parboiling mills or dryers. Rapid and efficient drying reduces milling breakage in rice harvested at high moisture content. Parboiling is even more effective at strengthening the rice grain against milling breakage by fusing together the starch grain when the paddy is cooked before milling; this also eliminates grain chalkiness (Bhattacharya, 1969). Buyers of green paddy, however, pay special attention to quality spoiling immature and incompletely filled grain. These become contaminants in milled rice, as they are smaller than the standard grain size, fail to mill properly, and may remain green or become discolored after processing. Removing this contamination by optical sorting is an essential step in the processing of rice varieties prone to this problem. The quoted price of the aromatic modern variety PTT1 is regularly defined as 'color sorted', i.e., the discolored grain has already been removed with an optical sorting machine.
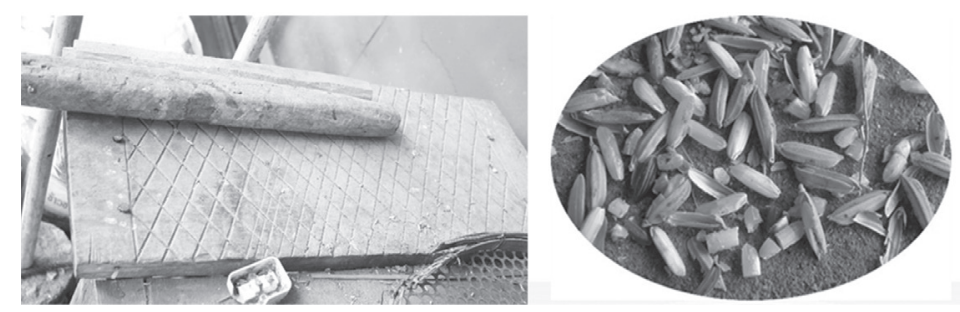

Figure 8. Paddy crushing board (left) and de-husked paddy sample (right).

Note: Photos by C. Prom-u-thai and B. Rerkasem. 


\section{Contamination}

Paddy rice contaminated with foreign matter (such as soil, sand, rocks, dirt, or fragments of straw or weeds) and/or non-standard grain (discolored, immature, or incompletely filled) is priced lower. Several factors can cause this latter contamination, including growing or storage conditions. The upper limit of the size of a single rice grain is fixed by its rigid hull, a genetically controlled characteristic in each variety (Chen et al., 1994; Zeng \& Shannon, 2000). The standard grain size for a variety (represented by the mode in frequency distribution of individual grain size) is constant; however, unfavorable growing conditions can cause a high proportion of the rice grain to fall below the standard size by incomplete filling to varying extents (Laenoi et al., 2017). Modern varieties grown in the cool season in Chiang Mai were found to be especially sensitive to this problem; the strongest effect was observed in the varieties CNT1 and PTT1, with more than $70 \%$ of the grain incompletely filled (Table 2). Kao Fun Noo (mouse tooth rice), the yellowish milled grain associated with fungal infestation that flourishes with the heating up of paddy stored with high moisture content, is another serious contaminant that can lower the price of rice (Phillips et al., 1988; Gras et al., 1989; Bason et al., 1990; Duangsrisai, 2012).

The mixing of non-glutinous and glutinous grain can also depress the price of rice, especially in the glutinous rice area of the North and Northeast (Figure 5), where glutinous and non-glutinous rice are often grown in neighboring fields or in the same field in alternating years. The translucent milled grain of non-glutinous rice is generally distinguishable from the opaque glutinous grain, but this difference is not completely reliable for determining price. Under certain conditions, the endosperm of some glutinous varieties may not turn opaque for

Table 2. Effects of season on grain filling in four modern Thai rice varieties.

\begin{tabular}{lccc}
\hline Variety (constant standard & Wet season & Cool season & Hot season \\
\cline { 2 - 4 } grain size in brackets $\left.{ }^{1}\right)$ & Incompletely filled and unfilled grain (\% by number) \\
\hline SPR1 (28 mg) & 12.6 & 49.1 & 30.4 \\
CNT1 (28 mg) & 12.1 & 70.7 & 27.9 \\
PTT1 (28 mg) & 14.4 & 73.1 & 25.5 \\
RD21 (35 mg) & 11.7 & 44.6 & 16.7 \\
\hline
\end{tabular}

Source: Laenoi, 2017; Laenoi et al., 2017.

Note: ${ }^{1}$ Identified by the mode in frequency distribution of individual grain size. 
some time after harvest. Alternatively, the opaque endosperm of Sang Yod, a uniquely superior quality rice from the south, contradicts its non-glutinous characteristic as revealed by the presence of amylose by an iodine staining test (Panomjan et al., 2016). Furthermore, it is possible to mistake heavily chalky, non-glutinous grain for glutinous grain. Given these factors, and the speed at which a large volume of paddy has to be evaluated at the height of the harvest season to set prices, this translucent/opaque distinction is inadequate. To rapidly and accurately assess the presence of amylose in quantitative terms, paddy buyers routinely use tincture of iodine as found in first aid kits (iodine in dilute potassium iodide or sodium iodide solution mixed with alcohol); the amylose starch in non-glutinous grain turns blue-black in the presence of iodine. Up to 5 grains in 100 of one or the other is al- lowed as normal in non-glutinous or glutinous rice admixtures, but buyers may reject contamination levels of 10 in 100 .

\section{REGULATING MILLED RICE QUALITY}

The setting of paddy price in the above section reflects the quality of milled rice that consumers expect and are willing to pay for. Domestic and international trade in Thai rice is also regulated by a set of laws on milled rice quality, first enacted in 1960 and amended most recently in 2016 (MoC, 2016a; 2016b; 2016c). Physical attributes of the milled grain define a common standard shared by all types of Thai rice for each grade, such as, $100 \%$, 5\%, and Broken, but with more detailed specification by variety, season of cultivation, and allowable contamination in the case of premium-quality, aromatic rice (Table 3 ).

Table 3. Legal quality standards for three main types of Thai rice.

\begin{tabular}{lr}
\hline a) General standard for 100\% milled rice & (\% by weight, or as otherwise indicated) \\
\hline Full grain: $\geq 9 / 10$ full kernel length & $\geq 60$ \\
Broken: & \\
$\geq 5 / 10-<8 / 10$ full kernel length & $\leq 4.5$ \\
$<5 / 10$ full kernel length, but does not pass through No. 7 screen $^{1}$ & $\leq 0.5$ \\
C1, passes through No. 7 screen & $\leq 0.1$ \\
Head rice: $\geq 8 / 10$ of full kernel length & Remainders \\
Allowable contamination & \\
Red rice or incompletely polished kernels & $\leq 0.5$ \\
Yellow kernels (Kao Fun Noo, mouse tooth rice) & $\leq 0.2$ \\
Visually detectable damaged kernels by mold, insects, etc. & $\leq 0.25$ \\
Immature or incompletely filled grains and other impurities & $\leq 0.2$ \\
Unhusked grains (paddy) & $\leq 5$ grains in $1 \mathrm{~kg}$ \\
\hline
\end{tabular}


Table 3. Continued.

b) General standard for 5\% milled rice

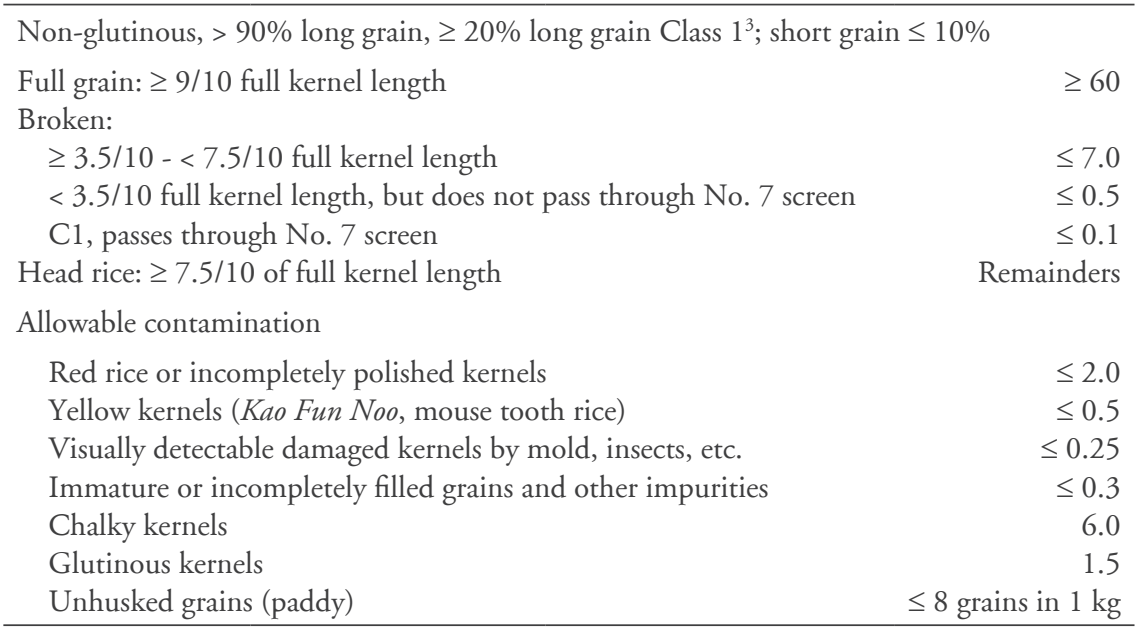

c) Type specific standard

\begin{tabular}{|c|c|c|c|}
\hline & White $100 \% \mathrm{~B}^{2}$ & Hom Mali $100 \%$ & Hom $100 \%$ \\
\hline \multirow[t]{2}{*}{ Specification } & $\begin{array}{l}\text { Non-glutinous, }> \\
95 \% \text { long grain, } \geq \\
40 \% \text { long grain Class } \\
1^{3} ; \text { short grain } \leq \\
5.0 \%\end{array}$ & $\begin{array}{l}\text { Wet-season grown } \\
\text { varieties KDML105 and } \\
\text { RD15; 13-18\% amylose } \\
\text { at } 14 \% \text { moisture, alkali } \\
\text { spreading value } 6-7\end{array}$ & $\begin{array}{l}\text { Certified aromat- } \\
\text { ic non-glutinous } \\
\text { varieties; } \leq 20 \% \\
\text { amylose at } 14 \% \\
\text { moisture, alkali } \\
\text { spreading value } \\
6-7\end{array}$ \\
\hline & \multicolumn{3}{|c|}{ (\% by weight, or as otherwise indicated) } \\
\hline Chalky kernels $^{4}$ & $\leq 6.0$ & $\leq 3.0$ & $\leq 6.0$ \\
\hline Glutinous kernels & $\leq 1.5$ & $\leq 1.0$ & $\leq 1.5$ \\
\hline
\end{tabular}

Source: Translated and summarized from MoC (2016a, 2016b, 2016c).

Note: ${ }^{1}$ No. 7 screen: metal sieve $0.79 \mathrm{~mm}$ thick, with $1.75 \mathrm{~mm}$ diameter round mesh; ${ }^{2}$ Benchmark rice in the global rice market; ${ }^{3}$ Long grain, class $1>7.0 \mathrm{~mm}$ length, class $2>6.6-7.0 \mathrm{~mm}$, class $3>6.2-6.6 \mathrm{~mm}$; short grain $\leq 6.2 \mathrm{~mm} ;{ }^{4}$ Opaque area covering $>50 \%$ of kernel.

The quality standard for Thai rice differs from the international standard in some important ways. Internationally, rice grain length is defined as extra-long (> $7.50 \mathrm{~mm})$, long $(6.61-7.5 \mathrm{~mm})$, medium $(5.51-6.5 \mathrm{~mm})$, or short (<5.5 mm) (Juliano, 1993). For Thai rice, a grain length of $\leq 6.2 \mathrm{~mm}$ is classified as short grain, and the long grain is divided into three classes: Class 1 (> $7.0 \mathrm{~mm})$, Class $2(6.6-7.0 \mathrm{~mm})$, and Class 3 (> $6.2-6.6 \mathrm{~mm}$ ).

Non-glutinous Thai rice is essentially all long grain, with grades differentiated by specified proportions (by weight) of Class 1 grains and an allowable proportion of short-grain rice as follows: 
- White rice $100 \%$ A must be $100 \%$ long grain, $\geq 70 \%$ in Class 1 ;

- White rice $100 \%$ B must be $\geq 95 \%$ long grain, $\geq 40 \%$ in Class 1 ;

- White rice $5 \%$ must be $\geq 90 \%$ long grain, $\geq 20 \%$ in Class 1 ;

- White rice $15 \%$ must be $\geq 70 \%$ long grain, $\geq 50 \%$ in Class 1 ;

- White rice $25 \%$ must be $\geq 50 \%$ long grain, made up of Classes 1, 2, or 3 , or mixtures.

Aromatic varieties are all milled into long grain Class 1, with genetically determined grain length for unpolished brown rice at $7.5 \mathrm{~mm}$ in the Hom Mali varieties KDML105 and RD15, and $7.5-7.8 \mathrm{~mm}$ for other certified aromatic varieties (Rice Department, 2016). Long-grain glutinous rice retails for $10-20 \%$ more than the short-grain type (Figure 7).

After milling, kernels with $\geq 9 / 10$ the length of intact grain are considered 'whole grain' and those with $\geq 8 / 10$ are classed as 'head rice'. Fragments of milled grain shorter than head rice are classified as 'broken'. The proportion of broken to whole grain and head rice is another key determinant of Thai rice quality. Broken remnants from the milling of $100 \%$ rice that are longer than one-half of the original kernel length, and include no more than 10\% byweightofgrainsshorter than one-half, are traded as 'Super Special A1 Broken'.

\section{VALUE ADDING TECHNOLOGIES}

Adoption of modern varieties has increased the productivity of rice land in Thailand by increasing the yield per area per season (Figure 4) and the number of crops that can be grown on the same plot in one year. In addition, cultivating aromatic and glutinous rice has increased the value of Thailand's annual rice crop by an estimated onethird over ordinary white rice because they command higher prices (96\% and $67 \%$ higher, based on 10-year average prices, respectively) (Figure 1). Technological development has also helped, especially mechanization of rice farming, which has resulted in a 12 -fold increase in rice yield per unit of labor (Rerkasem, 2015).

Although countries and cultures define rice quality differently, all markets value whole grain more than broken grain (Unnevehr et al., 1992). Combine harvesting, mechanical drying, and parboiling have all helped reduce milling breakage, and thus raised the value of Thai rice by increasing the milling yield of higher-priced full grain and head rice. Combine harvesters allow for rapid and timely harvest. This prevents the grain from becoming too dry and brittle, the norm with manual harvesting facing severe labor shortages, which produces largely broken rice when milled. The advent of relatively inexpensive, locally developed and manufactured combine harvesters has enabled farmers to harvest and thresh rice with high moisture content (Thepent \& Chamsing, 2009), as well as save on labor costs.

While combine harvesting is efficient, it must be combined with immediate processing to maintain the quality of its high moisture content paddy. The well-timed development of mechanical drying and parboiling has made this possible. Given the clear economic benefits, paddy dealers and mills have 
been quick to build paddy drying facilities; however, the convergence of paddy prices when adjusted to the same water content has discouraged farmers from doing the same, despite government support to do so (Thepent \& Chamsing, 2009). When milled, one ton of parboiled paddy yields $580 \mathrm{~kg}$ of head rice and $70 \mathrm{~kg}$ of broken grain; in contrast, one ton of raw paddy yields $390 \mathrm{~kg}$ of head rice and $260 \mathrm{~kg}$ of broken grain - a dramatic difference in the ratio of head rice to broken grain (Siamwalla \& Na Ranong, 1990). Lacking access to drying and storage facilities, however, farmers are forced to sell their rice as soon as they harvest it, when prices are lowest, which frequently occurs during and immediately following the main harvest season in November and December.

Converting rice husk into fuel has also added value. The rice husk, once a waste product of milling rice, now provides energy as a biofuel, including for rice processing itself. Burning one kilogram of rice husk produces approximately the same amount of energy as one-half liter of diesel fuel; as rice milling in Thailand produces some five million tons of rice husk annually, this is an important biofuel source (Peerapong \& Limmeechokchai, 2009).

Finally, extracting oil from rice bran has also added value to Thailand's rice value chain. Formerly, rice bran was primarily fed to pigs and poultry. Now, more efficient oil extraction and refining methods has increased its value, with the detection of compounds with commercial applications in substantial concentrations, including $\gamma$-oryzanol, vitamin $\mathrm{E}$, and especially the rarer and higher priced tocotrienol (Sundram et al., 2003; Patel \& Naik, 2004; NIA, 2006), making rice bran oil considerably more expensive than competing sources of vegetable oils, such as soybean, palm, and rapeseed.

\section{LOCAL FAVORITES AND SPECIAL QUALITY RICE}

Local varieties, excluding those designated improved by plant breeding such as KDML105, RD6, and RD15, accounted for only 0.5 million ha of cropland in Thailand in 2013, down from 1.5 million ha in 1996 (OAEs, 1998; 2014). However, while they accounted for only $4 \%$ of the main season production, they include several varieties of local importance, as well as many with promising new traits. Local rice varieties provide an invaluable resource for both growers and consumers in areas unreachable by varieties from the national rice breeding program for ecological or socio-economic reasons. These include the highlands (Unthong et al., 2007), areas prone to annual flooding (Sommut, 2003), and the southern provinces that are influenced by not only the Southwest monsoon that governs rice production in the rest of the country, but also the Northeast monsoon. Several adaptive traits have been definitely verified that allow the rice crop to grow and yield reasonably well in these niches, including tolerance to locality-specific biotic stresses of insect pests (Oupkaew et al., 2011), disease (Naruebal, 2009), the physical 
constraints of soil acidity (Phattarakul, 2008), and flooding of various depths and durations (Sommut, 2003). Those who grow rice for their own consumption directly benefit from the local varieties that are especially rich in the micronutrients iron and zinc (see Prom-u-thai $\&$ Rerkasem, 2004; Saenchai et al., 2012; Jaksomsak et al., 2015; Jamjod et al., 2017).

Due to emerging interest in rice of special quality, several local varieties have developed a national or international reputation and gained market share. Most notable are those varieties with pigmented pericarp, for their putative health benefits and commercialization potential. These include long-established local varieties, such as Sang Yod, a variety with reddish brown pericarp from Songkhla Lake Basin the South (Saetan, 2010; Panomjan et al., 2016), Kao Kam or Kao Niaw Dam (black or purple glutinous rice) from the North and Northeast, and Pi-i-su (black glutinous rice) from the highlands (see Boonsit et al., 2010; Rerkasem, 2015; Jamjod et al., 2017); and newly developed varieties, such as Hom Nil or Hom Mali Nil (black Hom Mali), Red Hom Mali (Htwe et al., 2010a; Htwe et al., 2010b; Pramai \& Jiamyangyuen, 2016), and Riceberry (Leardkamolkarn et al., 2011; Posuwan et al., 2013).

A series of transforming steps in the midstream and downstream sections of the Thai rice value chain have facilitated the commercialization of local rice varieties with limited production volume. This began with the development of small- to medium-sized modern rice mills that process $0.5-20 \mathrm{t}$ of paddy per day, followed by packaging and branding at the mills for direct delivery to retail outlets, as has reportedly happened in China (Reardon et al., 2014), and for export in some cases. These local mills, operating either as cooperative or private enterprises, adequately serve the urban populations in provincial towns, districts, and municipalities, who are expected to outnumber those living on the farm by 2020 , with milled rice of a quality comparable to that from large industrialsized mills. Some have responded to local preferences and branched out into processing speciality rice. The privatelyowned Charoen Tanyakij Rice Mill in Ratchaburi operates a 20-ton per day mill to process a local variety called Luang On, as well as Hom Mali and CNT1, marketed under their own brand (Charoenchon, 2012). Other mills specialize in local varieties with already established reputations, such as Khao Gaw Diaw from deep water areas in Phichit and Jek Chuey from Saraburi. A 12-ton per day mill operated by the Ban Khao Klang Community Enterprise of Patthalung province in southern Thailand annually processes $350 \mathrm{t}$ of Sang Yod paddy grown by its members into high-priced, unpolished, pigmented rice to supply national supermarket chains and for export (Thanonkaew, 2016). The involvement of farmers in the retail market for milled rice has shortened the rice value chain. Very recently, social media has exploded with offers of milled rice for sale, but this market will require time to stabilize, including ensuring a reliable and quality product. 
The decentralization of the midstream and downstream sections of the Thai rice value chain has also enabled some farmers, communities, and companies to benefit from producing other speciality rice, such as organic and Japonica rice. Although the total volume of certified organic Hom Mali rice is miniscule, representing only $0.1 \%$ of national production in 2016 (RPDD, 2017), 37 communities in the Northeast and North have benefitted from its production by integrating closely with the midstream and downstream section of the value chain; i.e., to process the rice they grow for direct sale to retail outlets both within and outside Thailand. Approximately 5,000 farming households in the upper North produce Japonica rice in a similar fashion, supplying the small community of Japanese expatriates in Thailand, as well as the Japanese restaurants popular among metropolitan Thais (Srikoom, 2016).

In conclusion, although grown from a single crop species, Thai rice comes in many different types, grades, and prices that are kept separate along different branches of the value chain. Upstream, farmers choose varieties and farm management practices in response to the market, local resource endowments, and preferences. Midstream, the paddy harvest from a multitude of farms is sorted into different types and grades for separate processing, storage, and marketing in response to consumer demand in different domestic and export markets; at the same time, this signals differential paddy prices back upstream to the farmers. Technological development has helped add value as well as segment the market for Thai rice. Downstream, new branches of the value chain have developed with the emergence of local specialty rice, facilitated by development of small- and medium-sized modern rice mills that allow farmers to enter the retail milled rice market directly.

\section{REFERENCES}

Bason, M.L., Gras, P.W., Banks, H.J., \& Esteves, L.A. (1990). A quantitative study of the influence of temperature, water activity, and storage atmosphere on the yellowing of paddy endosperm. Cereal Chemistry, 12, 193-201. https://doi.org/10. 1016/S0733-5210(09)80101-X

Bhattacharya, K.R. (1969). Breakage of rice during milling and effect of parboiling. Cereal Chemistry, 46, $478-485$.

Boonsit, P., Pongpiachan, P., Julsrigival, S., \& Karladee, D. (2010). Gamma oryzanol content in glutinous purple rice landrace varieties. Chiang Mai University Journal of Natural Science, 9(1), 151-157.

Brookfield, H. (2001). Exploring Agrodiversity. New York: Columbia University Press.

Charoenchon, C. (2012). A study of business strategy for growth in rice milling business: Case study of Charoen Tanyakij Rice Mill, Ratchaburi. (MS Thesis). University of the Thai Chamber of Commerce, Bangkok. In Thai 
Chen, C.L., Li, C.C., \& Sung, J.M. (1994). Carbohydrate metabolism enzymes in $\mathrm{CO}_{2}$-enriched developing rice grains of cultivar varying in grain size. Physiologia Plantarum, 90, 79-85. https://doi.org/10.1111/ j.1399-3054.1994.tb02195.x

Demont, M., \& Ndour, M. (2015). Upgrading rice value chains: Experimental evidence from 11 African markets. Global Food Security, 5, 70-46. https://doi.org/10.1016/j.gfs. 2014.10.001

DFT. (2011). Promotional and public relations activities on Thai Hom Mali Rice standard. Department of Foreign Trade. In Thai. Retrieved from http://www.dft.go.th/th-th/ Service-DFT/Service-Information/DATA-Group-Product/ Detail-DATA-Group-Product/ ArticleId/7494/dft-Thai-jasminerice- 22

Duangsrisai, S. (2012). Policy support for post-harvest technology: improving rice quality for better price. (Thailand Research Fund Policy Brief 3(21/ 2555)). In Thai. Retrieved from http://prp.trf.or.th/trf-policybrief/

Fitzgerald, M.A., McCouch, S.R., \& Hall, R.D. (2009). Not just a grain of rice: the quest for quality. Trends in Plant Science, 14, 133-139. https://doi.org/10.1016/j.tplants. 2008.12.004
Gras, P.W., Banks, H.J., Bason, M.L., \& Arriola, L.P. (1989). A quantitative study of the influences of temperature, water activity and storage atmosphere on the yellowing of milled rice. Journal of Cereal Science, 9(1), 77-89. https://doi.org/ 10.1016/S0733-5210(89)80026-8

Htwe, N.N., Srilaong, V., Tanprasert, K., Tongchitpakdee, S., Kanlayanarat, S., \& Uthairatanakij, A. (2010a). Effects of storage time and temperature on radical scavenging activities and bioactive compounds in colored rice varieties. Journal of Food, Agriculture and Environment, 8, 26-31.

Htwe, N.N., Srilaong, V., Tanprasert, K., Photchanachai, S., Kanlayanarat, S., \& Uthairatanakij, A. (2010b). Low oxygen concentrations affecting antioxidant activity and bioactive compounds in coloured rice. Asian Journal of Food and Agro-Industry, 3, 269-281.

Hussain A.A., Muarya, D.M., \& Vaish, C.P. (1987). Studies on quality status of indigenous upland rice (Oryza sativa). Indian Journal of Genetics, 47, 145-152.

IRRI. (2015). Rice Production Manual. Los Baños, Philippines: International Rice Research Institute.

Jaksomsak, P., Yimyam, N., Dell, B., Prom-u-thai, C., \& Rerkasem, B. (2015). Variation of seed zinc in a local upland rice germplasm from Thailand. Plant Genetic Resources, 13, 168-175. https://doi.org/10. 1017/S1479262114000872 
Jamjod, S., Yimyam, N., Lordkaew, S., Prom-u-thai, C., \& Rerkasem, B. (2017). Characterization of on-farm rice germplasm in an area of the crop's center of diversity. Chiang Mai University Journal of Natural Science, 16, 85-98. https://doi.org/ 10.12982/cmujns.2017.0007

Juliano, B.O. (1993). Rice in human nutrition. Rome: Food and Agriculture Organization of the United Nations.

Juliano, B.O., \& Villareal, C.P. (1993). Grain quality evaluation of world rices. Los Baños, Philippines: International Rice Research Institute.

Kaosa-ard, M.S., \& Rerkasem, B. (2000). The growth and sustainability of agriculture in Asia. Asian Development Bank's Study of Rural Asia: Beyond the Green Revolution, Volume 2. New York: Oxford University Press.

Laenoi, S. (2017). Genotypic and environmental control of grain quality in Thai rice. ( $\mathrm{PhD}$ Thesis (Agronomy)). Graduate School, Chiang Mai University, Chiang Mai.

Laenoi, S., Rerkasem, B., Lordkaew, S., \& Prom-u-thai. C. (2017). Seasonal variation in grain yield and quality in different rice varieties. Field Crops Research. Online. https://doi.org/10. 1016/j.fcr.2017.06.006

Leardkamolkarn, V., Thongthep, W., Suttiarporn, P., Kongkachuichai, R., Wongpornchai, S., \& Wanavijitr, A. (2011). Chemopreventive properties of the bran extracted from a newlydeveloped Thai rice: The Riceberry. Food Chemistry, 125, 978-985. https://doi.org/10.1016/j.foodchem.2010.09.093
Leesawatwong, M., Jamjod, S., \& Rerkasem, B. (2003). Determinants of a premium priced special quality rice. International Rice Research Notes, 28, 34.

Lipton, M., \& Longhurst, R. (1989). New seeds for poor people. Baltimore: Johns Hopkins University Press.

Little, R.R., Hilder, G.B. \& Dawson, E.H. (1958). Differential effect of dilute alkali on 25 varieties of milled white rice. Cereal Chemistry, 35, 111-126.

Maneechote, C., Jamjod, S., \& Rerkasem, B. (2004). Invasion of weedy rice in rice fields in Thailand: problems and management. International Rice Research Notes 29, 2, 20-22.

Mohapatra, D., \& Bal, S. (2005). Cooking quality and instrumental textural attributes of cooked rice for different milling fractions. Journal of Food Engineering, 73, 253-259. https://doi.org/10.1016/ j.jfoodeng.2005.01.028

MoC. (2016a). Ministry of Commerce announcement on Thai Hom Mali Rice Standard. Royal Gazette, 133 (special 243d), 5.

MoC. (2016b). Ministry of Commerce announcement on Hom (Aromatic, Jasmine or Fragrant) Rice Standard. Royal Gazette, 133 (special 243D), 12.

MoC. (2016c). Ministry of Commerce announcement on White Rice Standard. Royal Gazette, 133 (special 243d), 14. 
Naruebal, S. (2009). Diversity of highland rice Bue Polo variety from Mae Hong Son Province. (Master's thesis). Graduate School, Maejo University, Chiang Mai.

NIA. (2006). National innovation award 2006. National Innovation Agency. Retrieved from http:// www.moe.go.th/news_center/ news25092549_10.htm

OAE. (1998). Report on the survey of main season rice, 1996/97 Season. (Agricultural Statistic Document No. 9/1998). Bangkok: Office of Agriculture Economics.

OAE. (2014). Main rice crop survey 2556/7. Bangkok: Office of Agricultural Economics, Thai Ministry of Agriculture and Cooperatives.

OAE. (2016a). Basic agricultural economic data 2015. Bangkok: Office of Agricultural Economics, Thai Ministry of Agriculture and Cooperatives.

OAE. (2016b). Agricultural statistics of Thailand 2015/16. Bangkok: Office of Agricultural Economics, Thai Ministry of Agriculture and Cooperatives.

OAE. (2017). Thailand agricultural trade statistics 2015. Bangkok: Office of Agricultural Economics, Thai Ministry of Agriculture and Cooperatives.

Oupkaew,P.,Pusadee,T.,Sirabanchongkran, A., Rerkasem, K., Jamjod, S., \& Rerkasem, B. (2011). Complexity and adaptability of a traditional agricultural system: case study of a gall midge resistant rice landrace from northern Thailand. Genetic Resource and Crop Evolution, 58, 361-372.
Panomjan, N., Jamjod, S., Rerkasem, B., Dell, B., \& Prom-u-thai, C. (2016). Khon Kaen Agriculture Journal, 44, 83-94. (In Thai, with English abstract, figures and tables).

Patel, M., \& Naik, S.N. (2004). Gammaoryzanol from rice bran oil - A review. Journal of Science and Industrial Research (India), 63, 569-578.

Peerapong, P., \& Limmeechokchai, B. (2009). Exergetic and thermoeconomic analyses of the rice-husk power plant in Thailand. Journal of Metals, Materials and Minerals, 19, 9-14.

Phattarakul, N. (2008). Genotypic variation in tolerance to acid soil of local upland rice varieties. ( $\mathrm{PhD}$ Thesis (Agronomy)). Graduate School, Chiang Mai University, Chiang Mai.

Phillips, S., Widjaja, S., Wallbridge, A., \& Cooke, R. (1988). Rice yellowing during postharvest drying by aeration and during storage. Journal of Stored Products Research, 24, 173-181. https://doi.org/10.1016/0022474X(88)90015-X

Poomipan, P., Latkanathinnawong, V., Pliumchareorn, C., Chomphuphiw, P., \& Thepsilvisut, O. (2017). Effect of high quality organic fertilizer on production of Suphan Buri 1 rice. Thammasat University Journal of Science and Technology, 25, 248259. 
Posuwan, J., Prangthip, P., Leardkamolkarn, V., Yamborisut, Y., Surasiang, R., Charoensiri, R., \& Kongkachuichai, R. (2013). Long-term supplementation of high pigmented rice bran oil (Oryza sativa L.) on amelioration of oxidative stress and histological changes in streptozotocin-induced diabetic rats fed a high fat diet; Riceberry bran oil. Food Chemistry, 138, 501-508. https://doi.org/10.1016/j.foodchem.2012.09.144

Prachachat Business-news Online. (2017, June 15). Prachachat. Retrieved from https://www.prachachat.net/news_detail.php?newsid $=1497434315$

Pramai, P., \& Jiamyangyuen, S. (2016). Chemometric classification of pigmented rice varieties based on antioxidative properties in relation to color. Songklanakarin Journal of Science and Technology, 38, 463-472.

Prom-u-thai, C. (2010). Case study 10: Rice quality evaluation. Agricultural research for local solutions and opportunities project, Public Policy Studies Institute, Chiang Mai University.

Prom-u-thai, C., \& Rerkasem, B. (2004). Variability in bioavailable iron in hand-pounded traditional rice varieties from a highland village in northern Thailand. International Rice Research Notes, 29, 47-48.
Ram, H., Rashid, A., Zhang, W., Duarte, A.P., Phattarakul, N., Simunji, S., ... Cakmak, I. (2016). Biofortification of wheat, rice and common bean by applying foliar zinc fertilizer along with pesticides in seven countries. Plant and Soil, 403, 389-401. https://doi.org/ 10.1007/s11104-016-2815-3

Reardon, T., Chen, K.Z., Minten, B. \& Adriano, L. (2012). The quiet revolution in staple food value chains in Asia. Asian Development Bank and International Food Policy Research Institute, 286 p.

Reardon, T., Chen, K.Z., Minten, B.T., Lourdes, A., Dao, T.A., Wang, J., \& Gupta, S.D. (2014). The quiet revolution in Asia's rice value chains. Annals of the New York Academy of Sciences, 1331, 106-118. https://doi. org/10.1111/nyas. 12391

Rerkasem, B. (2007). Having your rice and eating it too: a view of Thailand's green revolution. ScienceAsia, 33 (S1), 75-80. https://doi.org/10.2306/ scienceasia 1513-1874.2007. 33(s1).075

Rerkasem, B. (2015). The Agroecosystem of Thai Rice: a Review. Chiang Mai University Journal of Natural Science, 14(1), 1-21. https://doi.org/10.12982/CMU JNS.2015.0068 
Rice Department. (2016). Rice varieties. Rice Knowledge Bank, Division ofRice Research and Development. Retrieved from http://www.rice thailand.go.th/Rkb/varieties/ index.php-file=content.php\&id $=$ 74.htm

RPDD. (2017). Organic farmers groups certified in 2016. Rice Product Development Division, Rice Department. Rettieved from http:// www.ricethailand.go.th/web/ images/pdf/GAPIN/ ORG59.pdf

Saenchai, C., Prom-u-thai, C., Jamjod, S., Dell, B., \& Rerkasem, B. (2012). Genotypic variation in milling depression of iron and zinc concentration in rice grain. Plant and Soil, 361, 271-278. https://doi. org/10.1007/s11104-012-1228-1

Saetan, S. (2010). Local rice varieties of southern Thailand volume II. Patthalung Rice Research Center, Bureau of Rice Research and Development, Rice Department, Bangkok.

Siamwalla,A., \&NaRanong, V. (1990). Pramual Kwam Roo Ruang Kao (Compilation of Knowledge on Rice). Thailand Development Research Institute, Bangkok. In Thai

Sommut, W. (2003). Changes in floodprone rice ecosystems in Thailand, Crop Year 2000-2001. Department of Agriculture, Thailand.
Srikoom, P. (2016). Japonica rice production in Thailand. Chiang Rai Rice Research Center. In Thai Retrieved from http://cri-rrc. ricethailand.go.th/images/sampledata/rice-cri/5japonica.pdf

Sundram, K., Sambanthamurthi, R. \& Tan, Y.-A. (2003). Palm fruit chemistry and nutrition, a review. Asia Pacific Journal of Clinical Nutrition, 12, 355-362.

Suwanarit, A., Kreetapirom, S., Buranakarn, S., Varanyanond, W., Tungtrakul, P., Somboonpong, S., .... Pornurisnit, P. (1996). Effect of nitrogen fertilizer on grain qualities of Khaw Dauk Mali-105 aromatic rice. Kasetsart Journal, Natural Sciences, 30, 458-474.

Thanonkaew, A. (2016). Development of Sangyod rice mill towards Good Manufacturing Practices for rice mill (GMP): A case study of Ban-Khao-Klang community enterprise. Area Based Research Journal, 8, 79-99. In Thai with English Abstract

Thepent, V., \& Chamsing, A. (2009, October). Agricultural mechanization development in Thailand. Paper presented at the $5^{\text {th }}$ Session of the Technical Committee of APCAEM, Los Banos, Philippines.

TMA. (2017). Rice prices. Thai Rice Mills Association. Retrieved from http://www.thairicemillers.com

TREA. (2017). Statistics. Thai rice exporters association. Retrieved from http://www.thairiceexporters.or.th/ List_\%20of_statistic.htm 
Unnevehr, L.J., Duff, B. \& Juliano, B.O. (Eds.). (1992). Consumer Demand for Rice Grain Quality. Terminal Report of IDRC Projects National Grain Quality (Asia) and International Grain Quality Economics (Asia) Los Baños, Philippines: International Rice Research Institute.

Unthong, A., Kaosa-ard, M., \& Punkiew, N. 2007. Factors affecting upland farmers' choice of local rice varieties in Thailand. Kasetsart University Journal of Economics, 14, 70-85. In Thai with English abstract
Wongtamee, A., Maneechote, C., Pusadee, T., Rerkasem, B., \& Jamjod, S. (2017). The dynamics of spatial and temporal population genetic structure of weedy rice (Oryza sativa f. spontanea Baker). Genetic Resource and Crop Evolution, 64, 23-39. https://doi. org/10.1007/s10722-015-0330-7

Zeng, L., \& Shannon, M.C. (2000). Salinity effects on seedling growth and yield components of rice. Crop Science, 40, 996-1003. 